\title{
Equatorial Enhancement of SSC Amplitudes: Solar Activity Dependence and Effect of Electric Field
}

\author{
A.R. JAIN and K.G. SRINIVASAcharya \\ Indian Institute of Geomagnetism, Colaba, Bombay, India \\ (Received March 29, 1976; Revised June 28, 1976)
}

\begin{abstract}
Characteristics of SSC amplitude at low and equatorial latitudes are studied using the data of 332 events observed simultaneously at three stations in the Indian region during the period 1958-1973. It is shown that during daytime both SSC amplitude in $H$ and its equatorial enhancement increase with increased solar activity. During nighttime also the SSC amplitudes are found to vary with solar activity. The daytime equatorial enhancement of SSC's, which is attributed to the currents in the ionospheric E-layer, shows much sharper variation with solar activity than that shown by conductivity in that layer or the jet current intensity. SSC's which occurred during partial counter electrojet events are examined to determine the effect of change in an ambient electric field on their amplitudes. It is found that a westward ambient electric field leads to a reduction in the equatorial enhancement.
\end{abstract}

\section{Introduction}

SSC's are known to be caused by the field changes produced by the impact of solar plasma on the geomagnetic field and are transmitted as hydromagnetic waves. These hydromagnetic waves exert a pressure on the upper atmosphere at an altitude of about $1,000 \mathrm{~km}$, thus causing compression of the ionosphere. This gives rise to a current flow at about $100 \mathrm{~km}$ height (Matsushita, 1962). It is well known that amplitudes of SSC's in $H$ are enhanced during daytime in the equatorial region (Sugiura, 1953; Forbush and Vestine, 1955; Maeda and Yamamoto, 1960; Srinivasamurthy, 1960; Rastogi et al., 1964). The diurnal variation of such enhancement in the Indian region was studied by Bhargava (1967), Trivedi and Rastogi (1968), Sastri and Jayakar (1970) and JAIN and SRINIVASACHARYA (1976). In a recent paper, MAYAud (1975) has shown that the yearly number of SSC events are well correlated with the yearly averages of sunspot number and that at a low latitude station (Colaba-Alibag, dip lat. $12^{\circ} 57^{\prime} \mathrm{N}$ ) there is no significant daily variation in SSC amplitude.

The daytime sudden commencement amplitude is significantly modulated 
by additional ionospheric $E$-region currents due to electric fields introduced through the compression of upper ionosphere by the hydromagnetic waves associated with the event. The magnitude of this electric field is controlled by the ambient electric field through the dynamics of the system. The additional current produced is, however, also determined by the conductivity in the region. Since the conductivity in the E-W direction is higher at the equator than at a corresponding low latitude station, the additional currents flowing during an SSC event in the $E$-region will also be larger at the equator. This is probably the primary mechanism of the equatorial enhancement which is thus influenced both by the conductivity and the ambient electric field. With this in mind, effect of the variation in the conductivity and electric fields in $E$-region on SSC amplitudes $(\delta H)$ at low and equatorial latitudes was studied by examining:

a) the effect of solar activity (and hence the conductivity variations) on SSC amplitude and its equatorial enhancement in the Indian region, and

b) the effect of counter electrojet (westward electric fields) on the equatorial enhancement of SSC's.

Amplitudes $(\delta H)$ of 332 events recorded simultaneously at the equatorial stations Trivandrum (TRV, dip lat. $0^{\circ} 18.3^{\prime} \mathrm{S}$ ), and Annamalainagar (ANR, dip lat. $2^{\circ} 43^{\prime} \mathrm{N}$ ) and a low latitude station Alibag (ALB) during the period 19581973 were used in the analysis.

\section{Effect of Solar Activity on SSC Amplitude}

Data for each year are divided into two time intervals (a) daytime: 7-17 hr $\left(75^{\circ} \mathrm{E}\right.$ time) and (b) nighttime: $19-05 \mathrm{hr}\left(75^{\circ} \mathrm{E}\right.$ time). Straight lines of the form

$$
A \bar{m} p=a\left(1+m \bar{R}_{\mathrm{z}}\right)
$$

Table 1. Coefficients $a$ and $m$ of the regression line, of the form in Eq. (1), fitted between average SSC amplitudes $A \bar{m} p$ and $\bar{R}_{\mathrm{z}}$.

\begin{tabular}{|c|c|c|c|c|c|}
\hline $\begin{array}{c}\text { Time } \\
\text { interval } \\
\left(75^{\circ} \mathrm{E} \text { time }\right)\end{array}$ & $\begin{array}{l}\text { No. of } \\
\text { data } \\
\text { sets }\end{array}$ & Station & $\begin{array}{c}a \\
\left(\mathrm{nT}^{1 /}\right)\end{array}$ & $\begin{array}{c}m \\
\left(\times 10^{-3}\right)\end{array}$ & $\begin{array}{c}\text { Correlation } \\
\text { coefficient } \\
\left(\gamma^{2)}\right)\end{array}$ \\
\hline \multirow[t]{3}{*}{$07-17$} & 16 & ALB & $14 \pm 1$ & $7 \pm 2$ & 0.83 \\
\hline & & TRV & $17 \pm 1$ & $15 \pm 3$ & 0.94 \\
\hline & & ANR & $19 \pm 1$ & $11 \pm 2$ & 0.94 \\
\hline \multirow[t]{3}{*}{$19-05$} & 16 & ALB & $15 \pm 2$ & $8 \pm 4$ & 0.62 \\
\hline & & TRV & $14 \pm 2$ & $8 \pm 4$ & 0.58 \\
\hline & & ANR & $17 \pm 2$ & $9 \pm 4$ & 0.63 \\
\hline
\end{tabular}

\footnotetext{
1) $\mathrm{nT}=10^{-9}$ Tesla $=10^{-5}$ Gauss.

2) $\gamma$ : correlation coefficient between $A \bar{m} P$ and $\bar{R}_{\mathrm{z}}$.
} 
are fitted to determine solar activity dependence of $\delta H . A \bar{m} p$ is the average amplitude of all the events which occurred in a particular year and during one of the two time intervals mentioned above and $\bar{R}_{\mathrm{z}}$ is the corresponding average of $R_{\mathrm{z}}$, the sunspot number for the day of the SSC event. Values of $a, m$ and $\gamma$, the correlation coefficient between $A \bar{m} p$ and $\bar{R}_{\mathrm{z}}$, are given in Table 1. From this table we note that:

a) Day and night values of $a$ and $m$ at ALB are about the same. This is in conformity with the result of MAYAUD (1975) and it shows that at this station ionospheric contribution to the SSC amplitude is not significant.

b) At TRV and ANR daytime values of $m$ are larger than the corresponding value for ALB.

c) During nighttime all the stations show the same solar activity variation $\left(m=8 \times 10^{-3}\right)$. Ratios $R_{\mathrm{T}}=\delta H_{\mathrm{TRV}} / \delta H_{\mathrm{ALB}}$ and $R_{\mathrm{A}}=\delta H_{\mathrm{ANR}} / \delta H_{\mathrm{ALB}}$ are found to be 0.95 and 1.15 for TRV and ANR, respectively.

Since our results show that there is no contribution of ionospheric origin to the SSC amplitude at ALB, the solar activity dependence is of extra ionospheric origin. This extra ionospheric contribution is probably due to the solar activity dependence of the size and particle content of the magnetosphere leading to the variations in the response of the cavity to the interplanetary shock waves and changes in the propagation characteristics of the hydromagnetic waves.

At equatorial stations, the daytime sudden commencement amplitude is known to have an ionospheric component also (MAEda and YамAMOTO, 1960). Our results show that there exists a solar activity dependence of the daytime SSC amplitude due to its ionospheric component in addition to a variation in the extraionospheric component determined for ALB.

Slight differences in amplitude, $\delta H$, of the nighttime SSC's at the three stations may be due to differences in the local subsurface electrical conductivity.

\section{Solar Activity Dependence of Equatorial Enhancement}

No equatorial enhancement of SSC amplitude was observed in the nighttime. The daytime augmentation is therefore of ionospheric origin. To separate this ionospheric component the following procedure was adopted. To account for the differences in the contribution of induced currents to $\delta H$ at the three stations $\delta H$ at TRV and at ANR were multiplied by $1 / R_{\mathrm{T}}$ and $1 / R_{\mathrm{A}}$, respectively. Percentage enhancement at the two equatorial stations, $E_{\mathrm{TRV}}$ and $E_{\mathrm{ANR}}$, was then calculated by:

$$
E_{\mathrm{TRV}}=\frac{\delta H_{\mathrm{TRV}}^{\prime}-\delta H_{\mathrm{ALB}}}{\delta H_{\mathrm{ALB}}} \quad \text { and } \quad E_{\mathrm{ANR}}=\frac{\delta H_{\mathrm{ANR}}^{\prime}-\delta H_{\mathrm{ALB}}}{\delta H_{\mathrm{ALB}}}
$$


where

$$
\delta H_{\mathrm{TRV}}^{\prime}=\delta H_{\mathrm{TRV}} / R_{\mathrm{T}} \text { and } \delta H_{\mathrm{ANR}}^{\prime}=\delta H_{\mathrm{ANR}} / R_{\mathrm{A}} .
$$

As the ionospheric effect at ALB is small, $E_{\mathrm{TRV}}$ and $E_{\mathrm{ANR}}$ give the equatorial enhancement of the amplitude at the two stations which is of ionospheric origin. $E_{\mathrm{TRV}}$ and $E_{\mathrm{ANR}}$ are now arranged in 6 bihourly intervals $(7-9,9-11,11-13,13-$ $15,15-17 \mathrm{hr}$ ). In Fig. $1 E_{\mathrm{ANR}}$ and $E_{\mathrm{TRV}}$ were plotted for a solar maximum year (1958) and average of two solar minimum years (1964 and 1965). From this figure we noted that the diurnal curve for equatorial enhancement during the solar minimum years showed a broad maxima while the corresponding curve for solar maximum year showed a sharp midday peak. This figure clearly indicates the effect of solar activity on daytime equatorial enhancement of SSC amplitude.

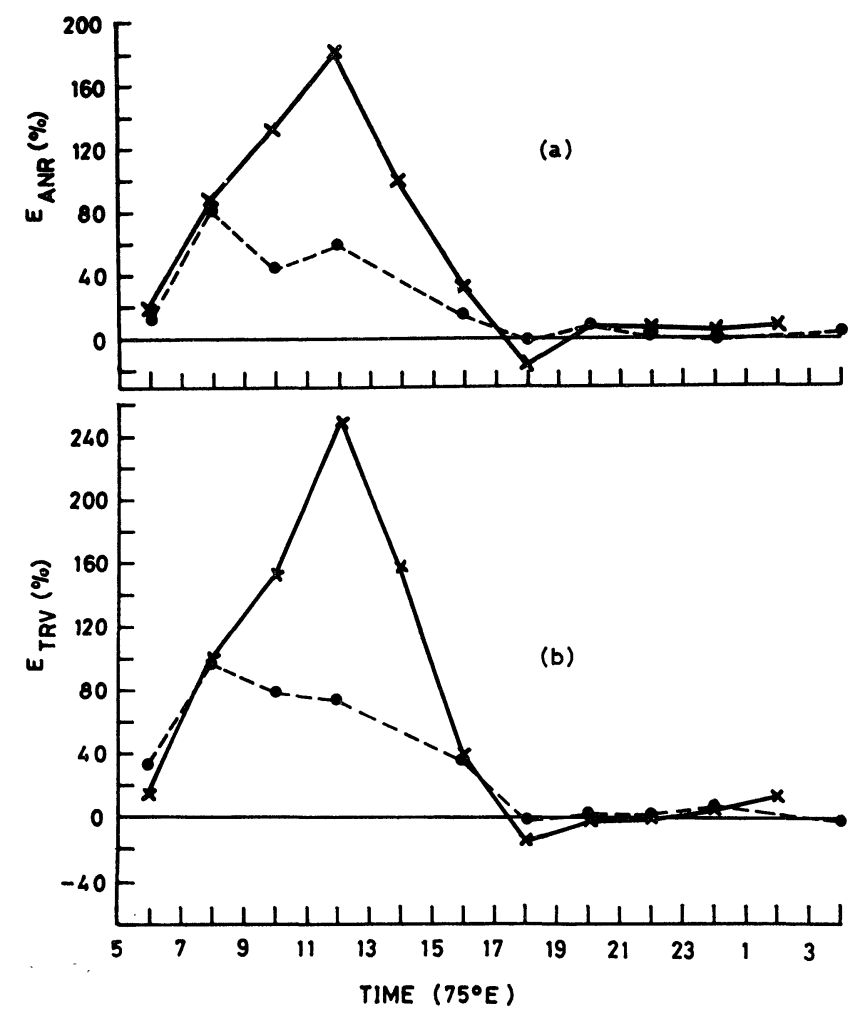

Fig. 1. Diurnal variation of percentage equatorial enhancement. The dashed line curve is for solar minimum years (1964 and 1965) and solid line is for solar maximum year (1958). (a) ANR, (b) TRV. 
Table 2. Coefficients $a$ and $m$ of the regression line, of the form in Eq. (1), fitted between percentage equatorial enhancement $\left(\bar{E}_{\mathrm{TRV}}\right.$ and $\left.\bar{E}_{\mathrm{ANR}}\right)$ and $\vec{R}_{\mathrm{z}}$.

\begin{tabular}{|c|c|c|c|c|c|c|}
\hline $\begin{array}{c}\text { Time } \\
\text { interval } \\
\left(75^{\circ} \mathrm{E} \text { time }\right)\end{array}$ & $\begin{array}{l}\text { Number } \\
\text { of data } \\
\text { sets }\end{array}$ & Station & $\begin{array}{c}a \\
(\%)\end{array}$ & $\begin{array}{c}m \\
\left(\times 10^{-3}\right)\end{array}$ & $\begin{array}{l}\text { Enhancement } \\
\text { for moderate } \\
\text { solar activity } \\
\left(R_{\mathrm{z}}=100\right)(\%)\end{array}$ & $\begin{array}{c}\text { Correlation } \\
\text { coefficient } \\
\left(\gamma^{1)}\right)\end{array}$ \\
\hline 07-09 & 12 & $\begin{array}{l}\text { TRV } \\
\text { ANR }\end{array}$ & \multicolumn{2}{|c|}{$\begin{array}{l}\text { No significant } \\
\text { dependence }\end{array}$} & $\begin{array}{l}92 \pm 11 \\
76 \pm 9\end{array}$ & $\begin{array}{l}0.01 \\
0.08\end{array}$ \\
\hline 09-11 & 13 & $\begin{array}{l}\text { TRV } \\
\text { ANR }\end{array}$ & \multicolumn{2}{|c|}{$\begin{array}{l}\text { No significant } \\
\text { dependence }\end{array}$} & $\begin{array}{l}93 \pm 8 \\
75 \pm 7\end{array}$ & $\begin{array}{l}0.26 \\
0.41\end{array}$ \\
\hline $11-13$ & 12 & $\begin{array}{l}\text { TRV } \\
\text { ANR }\end{array}$ & $\begin{array}{l}58 \\
39\end{array}$ & $\begin{array}{l}10 \\
13\end{array}$ & $\begin{array}{r}119 \pm 12 \\
90 \pm 8\end{array}$ & $\begin{array}{l}0.64 \\
0.69\end{array}$ \\
\hline $13-15$ & 11 & $\begin{array}{l}\text { TRV } \\
\text { ANR }\end{array}$ & $\begin{array}{l}35 \\
37\end{array}$ & $\begin{array}{r}14 \\
6\end{array}$ & $\begin{array}{l}85 \pm 7 \\
60 \pm 5\end{array}$ & $\begin{array}{l}0.77 \\
0.62\end{array}$ \\
\hline $15-17$ & 12 & $\begin{array}{l}\text { TRV } \\
\text { ANR }\end{array}$ & $\begin{array}{l}\text { No s } \\
\text { dep }\end{array}$ & $\begin{array}{l}\text { aificant } \\
\text { dence }\end{array}$ & $\begin{array}{l}30 \pm 6 \\
22 \pm 5\end{array}$ & $\begin{array}{l}0.41 \\
0.52\end{array}$ \\
\hline
\end{tabular}

1) $\gamma$ : correlation coefficient between $\bar{E}_{\mathrm{TRV}}, \bar{E}_{\mathrm{ANR}}$ and $\bar{R}_{\mathrm{Z}}$.

Solar activity dependence of $E_{\mathrm{TRV}}$ and $E_{\mathrm{ANR}}$ is determined for each of the 6 bihourly intervals and straight lines of the form given in Eq. (1) are fitted between the $\bar{E}_{\mathrm{TRV}}, \bar{E}_{\mathrm{ANR}}$ and $\bar{R}_{\mathrm{z}}$. The bars denote average for the year. Values of $a$ and $m$ are given in Table 2. In this table $\gamma$ is the correlation coefficient between $\bar{E}_{\mathrm{TRV}}, \bar{E}_{\mathrm{ANR}}$ and $\bar{R}_{\mathrm{z}}$. Computed values of $\bar{E}_{\mathrm{TRV}}$ and $\bar{E}_{\mathrm{ANR}}$ for moderate solar activity $\left(R_{\mathrm{z}}=100\right)$ are also given in this table. From this table significant solar activity dependence of enhancement can be noted between 11 to $15 \mathrm{hr}$ $\left(75^{\circ} \mathrm{E}\right.$ time). The average value of $m$ for the two stations for this period is equal to $(10 \pm 2.5) \times 10^{-3}$. This value is significantly higher than $m=6 \times 10^{-3}$ determined by us for quiet day range at TRV and ANR, $m=4.5 \times 10^{-3}$ for jet current intensity by RAO et al. (1967) and $m=4 \times 10^{-3}$ for the peak electron density of E-layer at low latitudes given by MAEdA and Fukao (1972). This shows that the solar activity dependence cannot be entirely due to the variations in the east-west conductivity. A significant contribution by other factors through the dynamics of the $E$-region is, therefore, indicated. The ambient electric fields, which can vary with height, are known to play an important role in dynamics of the equatorial ionosphere. They can, therefore, be expected to affect the amplitude and thereby the equatorial enhancement of the SSC. This aspect of the problem is discussed in the next section.

\section{Effect of Electric Fields}

The counter electrojet (CEJ) is an equatorial daytime phenomenon involving a depression of the $H$ value below the nighttime base line. A depression in 
$H$ at an equatorial station which is not large enough to bring the field below the nighttime level but enough to produce an equatorial minimum in $\Delta H$ (i.e. value of $H$ above the nighttime datum line) defines a partial counter electrojet (PCEJ) event. These events occur more frequently in the afternoon hours in the Indian region and during the solar minimum years. The phenomenon is most pronounced near the dip equator (RAstogi, 1973). During CEJ and PCEJ events electric fields at an altitude of $100 \mathrm{~km}$ which are normally eastward turn westward (RASTOGI, 1975). Influence of the ambient electric field on SSC amplitudes can, therefore, be brought out by examining events which occur during a CEJ or PCEJ.

Magnetograms of the 47 days on which SSC occurred during the afternoon hours $(1300$ to $1700 \mathrm{hr})$ were examined. From the $H$ field at TRV and ALB, the value of the field at the respective stations, for the night before (i.e. average of 2300 to $0100 \mathrm{hrs}$ ) was subtracted to obtain $\Delta H_{\mathrm{TRV}}$ and $\Delta H_{\mathrm{ALB}}$, the field due to the day time $E$-region currents. For the counter electrojet both $\Delta H_{\mathrm{TRV}}$ and $\left(\Delta H_{\mathrm{TRV}}-\Delta H_{\mathrm{ALB}}\right)$ should be negative while for the partial counter electrojet $\left(\Delta H_{\mathrm{TRV}}-\Delta H_{\mathrm{ALB}}\right)$ is negative but $\Delta H_{\mathrm{TRV}}$ remains positive. These criteria were suggested by RAstogi (1975).

Out of 47 SSCs seen in the afternoon hours, 14 occurred during CEJ or PCEJ events. The dates corresponding to these events are given in Table 3. In Fig. 2, one such event (SSC of 10.6.1973) is shown. In Fig. $3 \Delta H_{\mathrm{TRV}}$, $\Delta H_{\mathrm{ALB}}$ and $\left(\Delta H_{\mathrm{TRV}}-\Delta H_{\mathrm{ALB}}\right)$ are depicted and the period of CEJ event is indicated by shaded area. From Table 3 , it can be noted that there are 4 cases

JUNE 101973
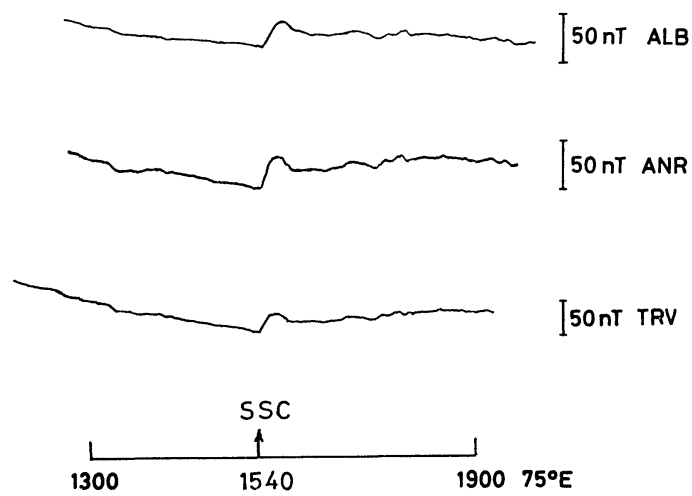

Fig. 2. SSC of 10.6.1973 at TRV, ANR, ALB ( $H$ element) which occurred during a CEJ event. No significant enhancement at the two equatorial stations was observed for this event. 
of no equatorial enhancement and 10 cases of positive equatorial enhancement at both the electrojet stations but with $\delta H_{\mathrm{ANR}} \geqq \delta H_{\mathrm{TRV}}$. The average amplitude of 14 SSC's occurring during CEJ/PCEJ show positive enhancement at the two equatorial stations with the enhancement greater for ANR than for TRV. For

Table 3. Dates on which SSC's occurred during CEJ/PCEJ event between 1300 to $1700 \mathrm{hr}\left(75^{\circ} \mathrm{E}\right.$ time $)$.

\begin{tabular}{rcll}
\hline Date of event & $\begin{array}{c}\text { Time of event } \\
\left(75^{\circ} \mathrm{E}\right)\end{array}$ & Number of events & Characteristic of SSC amplitude \\
\hline 13. 7.1961 & 1612 & 4 & \\
9. 3.1966 & 1556 & & No significant enhancement \\
26. 7.1969 & 1654 & $\delta H_{\mathrm{TR} V} \sim \delta H_{\mathrm{ANR}} \sim \delta H_{\mathrm{ALB}}$ \\
10. 6.1973 & 1540 & 10 & \\
\hline 23. 4.1959 & 1536 & Positive enhancement at both the \\
2. 9.1960 & 1658 & stations but enhancement at TRV \\
21. 9.1964 & 1648 & & is less than ANR. \\
15. 6.1965 & 1558 & $\delta H_{\mathrm{TRV}}>\delta H_{\mathrm{ALB}}, \delta H_{\mathrm{ANR}}>\delta H_{\mathrm{ALB}}$ \\
30. 8.1966 & 1612 & but $\delta H_{\mathrm{TRV}} \leqq \delta H_{\mathrm{ANR}}$ \\
15.10.1966 & 1455 & & \\
20. 4.1970 & 1622 & & \\
18. 1.1971 & 1400 & & \\
21. 1.1972 & 1651 & & \\
20. 4.1972 & 1550 & & \\
\hline
\end{tabular}

Last column gives the characteristic of SSC amplitude at the three stations.
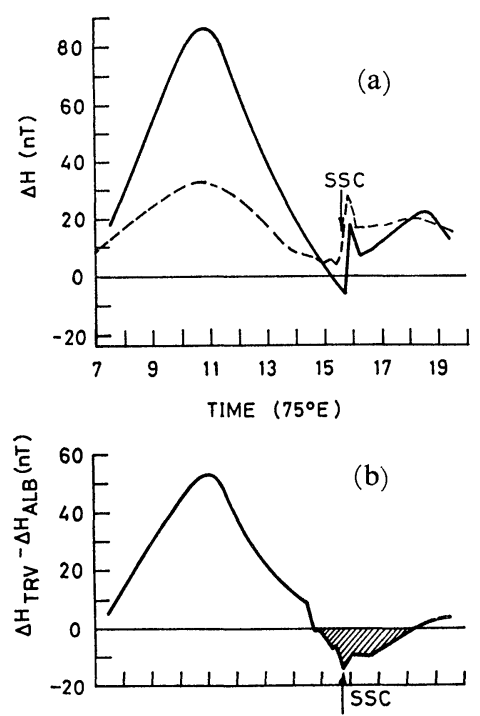

Fig. 3. (a) $\Delta H_{\mathrm{TRV}}$ and $\Delta H_{\mathrm{ALB}}$ for 10.6.1973. Dashed line curve is for ALB and solid line curve is for TRV. (b) $\Delta H_{\mathrm{TRV}}-\Delta H_{\mathrm{ALB}}$ for 10.6.1973. Shaded area shows the period of CEJ event on this day. 
the remaining 33 events occurring during afternoon hours, the average enhancement is found to be larger at TRV than at ANR. The westward electric fields at $E$-region heights thus tend to reduce the enhancement at TRV, a station under the axis of electrojet, with respect to ANR, which is a station nearer the boundary of the electrojet. These results show that apart from the conductivity, the electric fields also play an important role in the enhancement mechanism.

During the normal eastward jet, high frequency turbulances caused by the electric field-dependent crossfield and two stream instabilities are known to be present in the equatorial $E$-region. These high frequency waves can interact with the low frequency waves associated with an SSC and supply energy to the latter. This is a possible mechanism through which electric field can affect the equatorial enhancement. During CEJ/PCEJ one of the instabilities i.e. the crossfield instability is known to disappear (RASTOGI, 1972, 1975) and in this situation enhancement is likely to be reduced.

\section{Conclusion}

A strong solar activity dependence is exhibited by the SSC amplitudes as well as their daytime equatorial enhancements. The daytime equatorial enhancement increases more rapidly with solar activity than the $E$-region electron density (conductivity) and the jet current intensity, showing thereby that the solar activity dependence of SSC enhancement cannot be entirely due to the variation of the east-west conductivity. SSC's occuring during counter electrojet and partial counter electrojet show that ambient westward electric fields tend to make their amplitude less at a station near the dip equator than at a station nearer the boundary of the jet. This establishes the importance of ambient electric fields in the phenomenon of equatorial enhancement. Amplitude of the equatorial SSC can be affected by electric fields through the interaction of SSC with electric field-dependent crossfield and two stream instabilities present in the jet region of equatorial ionosphere. This is suggested as a possible mechanism.

We are thankful to our colleagues Dr. R. Rajaram, Mr. B.R. Arora, Dr. G.S. Lakhina and Mr. N.S. Sastri for many helpful discussions.

\section{REFERENCES}

Bhargava, B.N., Sudden commencement amplitudes and storm ranges in the Indian equatorial region, Ind. J. Met. Geophys., 18, 267-272, 1967.

ForbuSh, S.E. and E.H. Vestine, Daytime enhancement of size of sudden commencements and initial phase of magnetic storms at Huancayo, J. Geophys. Res., 60, 299-316, 1955. 
JAIN, A.R. and K.G. SRINIVASAChARYA, Diurnal variation of enhancement of magnetic pulsations and SSC in the Indian equatorial region. Proceedings of Symposium on Equatorial Geomagnetic Phenomena, held at the Indian Institute of Geomagnetism, Bombay, 15-16 May 1975, 138-142, 1976.

Maeda, H. and M. Yамамото, A note on the daytime enhancement of amplitude of geomagnetic storm sudden commencements in the equatorial region, J. Geophys. Res., 65, 2538-2539, 1960.

MAEDA, K. and S. FuKao, Study on the solar activity dependence of the E-region peak electron density and some atmospheric parameters, J. Geomag. Geoelectr., 24, 289-301, 1972.

Matsushita, S., On geomagnetic sudden commencements, sudden impulses and storm durations, J. Geophys. Res., 67, 3753-3777, 1962.

MaYaud, P.N., Analysis of storm sudden commencements for years 1868-1967, J. Geophys. Res., 80, 111-122, 1975.

RaO, K.N., D.R.K. RaO, and K.S. RaJa Rao, Sunspot cycle and seasonal variations in the position and intensity of the equatorial electrojet, Tellus, 19, 337-345, 1967.

Rastogi, R.G., Equatorial sporadic E and plasma instabilities, Nature (Physical Science), 237, 73-75, 1972.

Rastogi, R.G., Counter equatorial electrojet currents in the Indian zone, Planet. Space Sci., 21, 1355-1365, 1973.

RASTOGI, R.G., On the simultaneous existence of eastward and westward flowing equatorial electrojet currents. Proc. Ind. Acad. Sci., 81A, 80-92, 1975.

Rastogi, R.G., N.B. Trivedi, and N.D. Kaushika, Some relation between sudden commencement in $H$ and equatorial electrojet, J. Atmosph. Terr. Phys., 26, 771-776, 1964.

SASTRI, N.S. and R.W. JAYAKAR, Equatorial enhancement of geomagnetic field in the Indian region, Ind. J. Met. Geophys., 21, 279-284, 1970.

SRINIVASAMURTHY, B., The diurnal variations of sizes of sudden commencements and impulses in the Kodaikanal magnetograms, Ind. J. Met. Geophys., 11, 64, 1960.

Sugrura, M., The solar diurnal variation in the amplitude of sudden commencements and geomagnetic storms at geomagnetic equator, J. Geophys. Res., 58, 558-559, 1953.

Trivedi, N.B. and R.G. Rastogi, Studies of sudden changes in $H$ and $Z$ at equatorial stations in the Indian zone, Ann. Geophys., 24, 1037-1043, 1968. 